\title{
A New Class of the Power Function Distribution: Theory and Inference with an Application to Engineering Data
}

\author{
Alya Al Mutairi $\mathbb{D}^{1},{ }^{1}$ Muhammad Z. Iqbal, ${ }^{2}$ Muhammad Z. Arshad, ${ }^{2}$ and Ahmed Z. Afify $\mathbb{i D}^{3}$ \\ ${ }^{1}$ Department of Mathematics, Faculty of Science, Taibah University, Medina, Saudi Arabia \\ ${ }^{2}$ Department of Mathematics and Statistics, University of Agriculture, Faisalabad 38000, Pakistan \\ ${ }^{3}$ Department of Statistics, Mathematics and Insurance, Benha University, Benha 13511, Egypt
}

Correspondence should be addressed to Ahmed Z. Afify; ahmed.afify@fcom.bu.edu.eg

Received 6 January 2022; Accepted 1 February 2022; Published 3 March 2022

Academic Editor: Melike Kaplan

Copyright (c) 2022 Alya Al Mutairi et al. This is an open access article distributed under the Creative Commons Attribution License, which permits unrestricted use, distribution, and reproduction in any medium, provided the original work is properly cited.

\begin{abstract}
In this study, a new class that generates optimal univariate models called a new exponentiated-G class of distributions is developed. Numerous complementary statistical properties are derived and discussed in detail for the newly exponentiated power function (EPF) distribution. All possible shapes of the probability density and hazard rate functions are sketched for selected values of parameters. Six accredited estimation methods are discussed, and their performance is assessed and compared by a simulation study. The applicability of the new class is evaluated by analyzing the automotive engineering sector data.
\end{abstract}

\section{Introduction}

Modeling complicated problems is an enigma for applied researchers and practitioners. They seem to be worried about dealing with a variety of lifetime datasets that particularly follows physical and natural sciences. For this, they are searching for simple and efficient models. Consequently, a power function (PF) distribution is explored. It is a simple lifetime model as exponential and Pareto distributions. The $\mathrm{PF}$ distribution is a special case of the beta distribution. For more details about the classical work of the PF distribution, see Dallas [1] who developed a relationship between the Pareto and PF variables through an inverse transformation. Furthermore, for a deep understanding of the characterization of the PF distribution, see some credible work of Meniconi and Barry [2], Saran and Pandey [3], Chang [4], Tavangar [5], and Ahsanullah et al. [6].

In the most recent times, attention towards the generalization of probability distributions has grown phenomenally high. For more insight, see the trustworthy work of Cordeiro and Brito [7], Zaka and Akhter [8], Al Mutairi et al. [9], Tahir et al. [10], Shahzad et al. [11], Ahsan-ul-Haq et al. [12], Okorie et al. [13], Abdul-Moniem [14], Hassan et al.
[15], Zaka et al. [16], Arshad et al. [17], Arshad et al. [18, 19], Al-Mutairi [20], Alzaatreh et al. [21], Gleaton and Lynch [22], Bourguignon et al. [23], Afify et al. [24], Tahir et al. [25], Aldahlan et al. [26], Aslam et al. [27], Balogun et al. [28], Afify et al. [29], Mansour et al. [30], Mahdavi and Kundu [31], Nassar et al. [32], Ijaz et al. [33], Klakattawi and Aljuhani [34], Afify et al. [35], Alsubie et al. [36], Ahmad et al. [37], and Nofal et al. [38].

To the best of our knowledge, the new class has not been discussed before, and it is the first time to explore the scenario particularly observed in the automobile sector. We develop a new class of distributions called the new exponentiated-G (NE-G) family and study one of its special submodels using the PF distributions as a baseline model. The studied model is called the exponentiated power function (EPF) distribution. The present study has some motivations as follows: (a) to develop new optimal models; (b) to advance the characteristics of the baseline models; (c) the density and hazard rate functions possess unimodal and bathtub-shaped curves, respectively; (d) to model the realtime scenario in the automobile sector.

This paper is outlined in the following sections. The development of the new class is presented in Section 2. A 
comprehensive discussion on mathematical and reliability measures is completed in Sections 3 and 4, respectively. Miscellaneous measures are discussed in Section 5. Six accredited estimation methods are discussed in Section 6. Simulation results are presented in Section 7. A lifetime application of the EPF distribution is discussed in Section 8, and finally, some conclusions are reported in Section 9.

\section{The New Exponentiated-G Class}

Tahir and Cordeiro [39] (Remarks 2 (ii)) developed the exponentiated generalized negative binomial $G$ class which is defined by the CDF:

$$
F(x ; \beth)=\frac{1-\left(1+\eta \gamma G(x ; \beth)^{\beta}\right)^{-(1 / \alpha)}}{1-(1+\eta \gamma)^{-(1 / \alpha)}} .
$$

Chesneau et al. [40] reparameterized the parameters of (1) and provided the following CDF:

$$
F(x ; \beth)=\frac{(1+\eta G(x ; \beth))^{1+(1 / \eta)}-1}{(1+\eta)^{1+(1 / \eta)}-1} .
$$

In this section, we provide a new generator of distributions that is very simple and capable of generating optimal alternative models. The new generator is called the new exponentiated-G class, and it is specified by the CDF:

$$
F(x ; \beth)=\frac{(1+G(x ; \beth))^{\alpha}-1}{2^{\alpha}-1}, \quad x \in \mathfrak{R},
$$

where $G(x ; \beth) \epsilon(0,1)$ is a CDF of any baseline (parent) distribution. It is based on a parametric vector $\beth>0$ depending on $(r \times 1), \alpha>0$ is a shape parameter, and $\left(1 / 2^{\alpha}-1\right)$ is a normalizing constant. $F(0 ; \beth)=0$, and $F(\infty ; \beth)=1$. It is noted that the new class reduces to the baseline model with $\alpha=1$.

The probability density function (PDF) $(f(x))$ and the hazard rate function (HRF) $(h(x))$ of the new class reduce to

$$
\begin{array}{ll}
f(x ; \beth)=\frac{\alpha \mathrm{g}(x ; \beth)(1+G(x ; \beth))^{\alpha-1}}{2^{\alpha}-1}, & x \in \mathfrak{R}, \\
h(x ; \beth)=\frac{\alpha g(x ; \beth)(1+G(x ; \beth))^{\alpha-1}}{2^{\alpha}-(1+G(x ; \beth))^{\alpha-1}}, & x \in \mathfrak{R},
\end{array}
$$

where $\mathrm{g}(x ; \beth)=d G(x ; \beth) / d x$.

The quantile function $(\mathrm{QF})(\mathrm{Q}(x))$ of the new class takes the form.

$$
Q(x)=G^{-1}\left(\left(1+\left(2^{\alpha}-1\right) p\right)^{\frac{1}{\alpha}}-1\right), \quad p \in(0,1) .
$$

2.1. EPF Distribution. In this section, we discuss some useful characteristics of the EPF distribution. The PF distribution is specified by the following CDF and PDF:

$$
G(x)=\left(\frac{x}{g_{0}}\right)^{\beta}, \quad \beta>0,0<x \leq g_{0}
$$

and

$$
\mathrm{g}(x)=\frac{\beta}{\left(\mathrm{g}_{0}\right)^{\beta}} x^{\beta-1}, \quad \beta>0,0<x \leq \mathrm{g}_{0} .
$$

To this end, we define the analytical expressions of CDF and PDF of the new EPF distribution with two shape parameters $\alpha$ and $\beta$. The CDF of the EPF distribution has the form (for $0<x \leq \mathrm{g}_{0}$ )

$$
F(x)=\frac{\left(1+\left(x / g_{0}\right)^{\beta}\right)^{\alpha}-1}{2^{\alpha}-1}, \quad \alpha, \beta>0 .
$$

Its $\mathrm{PDF}$ reduces to

$$
\begin{aligned}
f(x)= & \frac{\alpha \beta}{\left(\mathrm{g}_{0}\right)^{\beta}\left(2^{\alpha}-1\right)}\left(\frac{1}{x^{1-\beta}}\right) \\
& \left(1+\left(\frac{x}{\mathrm{~g}_{0}}\right)^{\beta}\right)^{-(1-\alpha)}, \quad \alpha, \beta>0,
\end{aligned}
$$

where $\left(1 / 2^{\alpha}-1\right)$ is the normalizing constant and $g_{0}$ is a possible maximum assured life of a component.

The EPF distribution brings an additional shape parameter $(\alpha>0)$ that modulates the skewness and kurtosis tail weights of the baseline model. We note that a new parameter may offer a better fit to the unimodal, increasing, U-shaped, and bathtub-shaped failure rate data. The EPF distribution reduces to the baseline model (power function) for $\alpha=1$.

2.2. Asymptotic Properties of PDF and CDF. Asymptotes of the CDF and PDF at $x \longrightarrow 0$ are given by

$$
\left.F(x)\right|_{x \rightarrow 0} \sim 0 \text { and }\left.f(x)\right|_{x \rightarrow 0} \sim 0 .
$$

Asymptotes of the CDF and PDF at $x \longrightarrow$ g are given by

$$
\left.F(x)\right|_{x \rightarrow \mathrm{g}_{0}} \sim 1 \text { and }\left.f(x)\right|_{x \rightarrow \mathrm{g}_{0}} \sim \frac{\alpha \beta(2)^{\alpha-1}}{\mathrm{~g}_{0}\left(2^{\alpha}-1\right)} .
$$

The derived expressions explore a dynamic effect of $\alpha$ on the asymptotes of $F(x)$ and $f(x)$.

2.3. Shapes of PDF. Here, we discuss different shapes of the PDF of the EPF distribution. Figure 1 presents some different curves of the PDF for various choices of EPF parameters. We note that these curves can be decreasing, decreasing-increasing, and can be upside-down bathtub for $\mathrm{g}_{0}=2$.

\section{Moments and Related Measures}

Theorem 1. Let $X$ follow the EPF distribution with two shape parameters $(\alpha, \beta>0)$; then, the $r$-th ordinary moment $\left(\mu_{r}^{\prime}\right)$ of $X$ has the form 

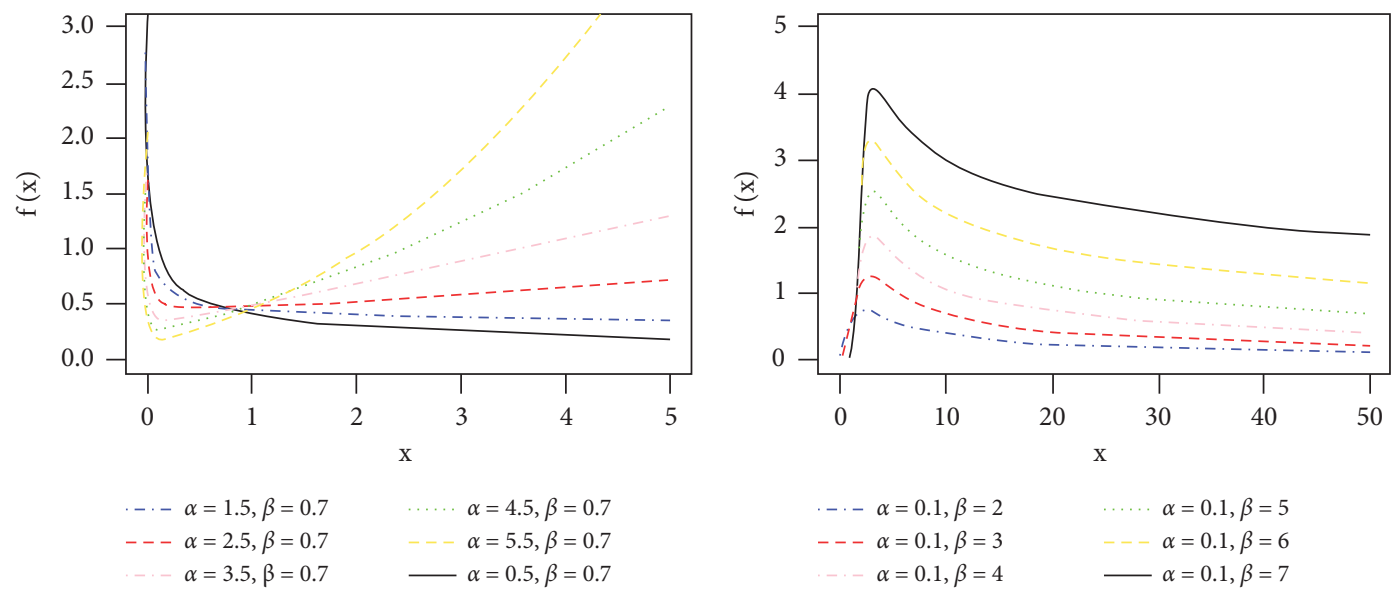

FIgURE 1: Some curves of PDF for EPF distribution.

$$
\mu_{r}=\frac{\alpha \beta}{\left(g_{0}\right)^{\beta}\left(2^{\alpha}-1\right)} \sum_{j=0}^{\infty} \psi_{j} \frac{\left(g_{0}\right)^{\Lambda_{r, j, \beta}}}{\Lambda_{r, j, \beta}} .
$$

Proof. The following expression follows using (6) as

$$
\mu_{r}=\frac{\alpha \beta}{\left(g_{0}\right)^{\beta}\left(2^{\alpha}-1\right)} \int_{0}^{g_{0}} x^{r} x^{\beta-1}\left(1+\left(\frac{x}{g_{0}}\right)^{\beta}\right)^{\alpha-1} d x .
$$

The prior expression can be rewritten by simplifying the expression $\left(1+\left(x / g_{0}\right)^{\beta}\right)^{\alpha-1}$ as follows:

$\mu_{r}=\frac{\alpha \beta}{\left(g_{0}\right)^{\beta}\left(2^{\alpha}-1\right)} \sum_{j=0}^{\infty}\left(\begin{array}{c}\alpha-1 \\ j\end{array}\right) \frac{1}{\left(g_{0}\right)^{\beta(j+1)}} \int_{0}^{g_{0}} x^{r+\beta(j+1)-1} d x$.

After some algebra, the $r$-th ordinary moment of $X$ reduces to

$$
\mu_{r}=\frac{\alpha \beta}{\left(g_{0}\right)^{\beta}\left(2^{\alpha}-1\right)} \sum_{j=0}^{\infty} \psi_{j} \frac{\left(g_{0}\right)^{\Lambda_{r, j \beta}}}{\Lambda_{r, j, \beta}},
$$

where $\psi_{j}=\left(\begin{array}{c}\alpha-1 \\ j\end{array}\right)\left(1 /\left(\mathrm{g}_{0}\right)^{\beta(j+1)}\right), \Lambda_{r, j, \beta}=r+\beta(j+1)$.

Table 1 presents some numerical results for the first-four ordinary moments $\left(\mu_{1}^{\prime}, \mu_{2}^{\prime}, \mu_{3}^{\prime}, \mu_{4}^{\prime}\right)$, variance $=\sigma^{2}$, skewness $=$ $\gamma_{1}$, and kurtosis $=\gamma_{2}$ for different values of the EPF parameters.

Table 1 shows flexible and versatile behavior for moments, variance and alongside the skewness and kurtosis. The results indicate that the EPF distribution can be discussed for leptokurtic and skewed datasets.

Corollary 1. The first and second ordinary moments and the inverse moment $\left(\mu_{-w}\right)$ can be obtained by substituting $r=$ 1,2 , and $-w$, in (7), respectively. The analytical expressions of mean, variance, and inverse moment are given, respectively, by

$$
\begin{aligned}
E(X)= & \mu_{1}=\frac{\alpha \beta}{\left(g_{0}\right)^{\beta}\left(2^{\alpha}-1\right)} \sum_{j=0}^{\infty} \psi_{j} \frac{\left(g_{0}\right)^{\Lambda_{1, j, \beta}}}{\Lambda_{1, j, \beta}}, \\
\operatorname{Var}(X)= & \frac{\alpha \beta}{\left(g_{0}\right)^{\beta}\left(2^{\alpha}-1\right)}\left(\sum_{j=0}^{\infty} \psi_{j} \frac{\left(g_{0}\right)^{\Lambda_{2, j, \beta}}}{\Lambda_{2, j, \beta}}-\frac{\alpha \beta}{\left(g_{0}\right)^{\beta}\left(2^{\alpha}-1\right)}\right. \\
& \left.\left(\sum_{j=0}^{\infty} \psi_{j} \frac{\left(g_{0}\right)^{\Lambda_{1, j, \beta}}}{\Lambda_{1, j, \beta}}\right)\right),
\end{aligned}
$$

and

$$
\mu_{-w} /=\frac{\alpha \beta}{\left(g_{0}\right)^{\beta}\left(2^{\alpha}-1\right)} \sum_{j=0}^{\infty} \psi_{j} \frac{\left(g_{0}\right)^{\Lambda_{-w, j ; \beta}}}{\Lambda_{-w, j, \beta}} .
$$

Corollary 2. The factorial generating function is obtained directly followed by $F_{x}(s)=E(1+s)^{x}=E\left(e^{x \ln (1+s)}\right)$ $=\sum_{r=0}^{\infty}\left((\ln (1+s))^{r} / r !\right) \mu_{r}^{\prime}$, and it can be written for $X$ as follows:

$F_{x}(s)=\frac{\alpha \beta}{\left(g_{0}\right)^{\beta}\left(2^{\alpha}-1\right)} \sum_{r=0}^{\infty} \frac{(\ln (1+s))^{r}}{r !} \sum_{j=0}^{\infty} \psi_{j} \frac{\left(g_{0}\right)^{\Lambda_{r, j \beta}}}{\Lambda_{r, j, \beta}}$.

Theorem 2. If $X \sim E P F(\alpha, \beta)$, then the moment generating function $(M G F)\left(M_{X}(s)\right)$ of $X$ is given by

$M_{X}(s)=\frac{\alpha \beta}{\left(g_{0}\right)^{\beta}\left(2^{\alpha}-1\right)} \sum_{r=0}^{\infty} \frac{s^{r}}{r !} \sum_{j=0}^{\infty} \psi_{j} \frac{\left(g_{0}\right)^{\Lambda_{r, j \beta}}}{\Lambda_{r, j, \beta}}, r=1,2, \ldots$.

Proof. The MGF $M_{X}(s)$ is defined as

$$
M_{X}(s)=\int_{0}^{g_{0}} e^{s x} f(x) d x .
$$


TABLE 1: Numerical analysis for moments, variance, skewness, and kurtosis.

\begin{tabular}{|c|c|c|c|c|c|c|c|c|c|}
\hline \multicolumn{3}{|c|}{ Parameters } & \multirow{2}{*}{$\begin{array}{c}\mu_{1}^{\prime} \\
1.3586\end{array}$} & \multirow{2}{*}{$\begin{array}{c}\mu_{2}^{\prime} \\
2.0621\end{array}$} & \multirow{2}{*}{$\begin{array}{c}\mu_{3}^{\prime} \\
3.3315\end{array}$} & \multirow{2}{*}{$\begin{array}{c}\mu_{4}^{\prime} \\
5.5933\end{array}$} & \multirow{2}{*}{$\begin{array}{c}\sigma^{2} \\
0.3245\end{array}$} & \multirow{2}{*}{$\begin{array}{c}\gamma_{1} \\
0.0011\end{array}$} & \multirow{2}{*}{$\begin{array}{c}\gamma_{2} \\
0.0340\end{array}$} \\
\hline \multirow{6}{*}{$\mathrm{g}_{0}=2$} & \multirow{5}{*}{$\alpha=1.5$} & $\beta=1.9$ & & & & & & & \\
\hline & & $\beta=0.9$ & 1.0044 & 1.3503 & 2.0370 & 3.2723 & 0.6662 & 0.0001 & 0.2197 \\
\hline & & $\beta=0.1$ & 0.3096 & 0.4915 & 1.0025 & 2.2783 & 0.4591 & 6.0526 & 7.7215 \\
\hline & & $\beta=0.2$ & 0.5586 & 0.9290 & 1.9286 & 4.4235 & 0.8209 & 2.4066 & 3.4680 \\
\hline & & $\beta=0.3$ & 0.7638 & 1.3215 & 2.7872 & 6.4478 & 1.1123 & 1.2730 & 2.0790 \\
\hline & $\beta=0.3$ & $\alpha=0.5$ & 0.6226 & 1.0334 & 2.1415 & 4.9061 & 0.8990 & 1.9872 & 2.9723 \\
\hline \multirow{4}{*}{$\mathrm{g}_{0}=3$} & & $\alpha=0.1$ & 0.5687 & 0.9272 & 1.9070 & 4.3511 & 0.8164 & 2.3676 & 3.4399 \\
\hline & $\beta=0.3$ & $\alpha=1.1$ & 0.7064 & 1.2029 & 2.5196 & 5.8065 & 1.0265 & 1.5233 & 2.3952 \\
\hline & $\beta=0.09$ & $\alpha=1.1$ & 0.2282 & 0.3561 & 0.7221 & 1.6358 & 0.3387 & 9.0647 & 11.1686 \\
\hline & $\beta=0.08$ & $\alpha=0.01$ & 0.1667 & 0.2553 & 0.5141 & 1.1608 & 0.2460 & 13.3676 & 16.0774 \\
\hline
\end{tabular}

Also, $e^{s x}=\sum_{r=0}^{\infty}\left((s x)^{r} / r !\right)$.

Hence, the MGF of $X$ is obtained as

$$
M_{X}(s)=\frac{\alpha \beta}{\left(g_{0}\right)^{\beta}\left(2^{\alpha}-1\right)} \sum_{r=0}^{\infty} \frac{s^{r}}{r !} \sum_{j=0}^{\infty} \psi_{j} \frac{\left(g_{0}\right)^{\Lambda_{r, j, \beta}}}{\Lambda_{r, j, \beta}} \text {. }
$$

Theorem 3.

If $X \sim E P F(\alpha, \beta)$, then the characteristic function $\left(\varphi_{X}(s)\right)$ of $X$ is given by

$$
\begin{aligned}
\varphi_{X}(s)= & \frac{\alpha \beta}{\left(g_{0}\right)^{\beta}\left(2^{\alpha}-1\right)} \sum_{r=0}^{\infty} \frac{(i s)^{r}}{r !} \\
& \sum_{j=0}^{\infty} \psi_{j} \frac{\left(g_{0}\right)^{\Lambda_{r, j, \beta}}}{\Lambda_{r, j, \beta}} ; r=1,2, \ldots \text { an } d i=\sqrt{-1} .
\end{aligned}
$$

Proof. The characteristic function $\varphi_{X}(s)$ is defined as

$$
\varphi_{X}(s)=\int_{0}^{g_{0}} e^{i s x} f(x) d x
$$

Hence, the characteristic function of $X$ is obtained as

$$
\varphi_{X}(s)=\frac{\alpha \beta}{\left(g_{0}\right)^{\beta}\left(2^{\alpha}-1\right)} \sum_{r=0}^{\infty} \frac{(i s)^{r}}{r !} \sum_{j=0}^{\infty} \psi_{j} \frac{\left(g_{0}\right)^{\Lambda_{r, j, \beta}}}{\Lambda_{r, j, \beta}} .
$$

Vitality function is defined as

$$
V(x)=\frac{1}{S(x)} \int_{x}^{g_{0}} x f(x) d x .
$$

It is obtained for $X$ as

$$
V(x)=\frac{1}{1-F(x)}\left(\frac{\alpha \beta}{\left(g_{0}\right)^{\beta}\left(2^{\alpha}-1\right)} \sum_{j=0}^{\infty} \psi_{j} \frac{\left(g_{0}\right)^{\Lambda_{1, j, \beta}}-(x)^{\Lambda_{1, j, \beta}}}{\Lambda_{1, j, \beta}}\right) .
$$

The conditional moments are defined as

$$
E\left(x^{r} \mid X>t\right)=\frac{1}{\bar{F}(t)} \int_{t}^{g_{0}} x^{r} f(x) d x .
$$

It is obtained for $X$ as

$E\left(x^{r} \mid X>t\right)=\frac{1}{1-F(t)}\left(\frac{\alpha \beta}{\left(g_{0}\right)^{\beta}\left(2^{\alpha}-1\right)} \sum_{j=0}^{\infty} \psi_{j} \frac{\left(g_{0}\right)^{\Lambda_{r, j, \beta}}-t^{\Lambda_{r, j, \beta}}}{\Lambda_{r, j, \beta}}\right)$.

\subsection{Incomplete Moments and Associated Measures}

Theorem 4. If $X \sim E P F(\alpha, \beta)$, then the $r$-th lower incomplete moments of $X$ are

$$
\Phi_{r}(t)=\frac{\alpha \beta}{\left(g_{0}\right)^{\beta}\left(2^{\alpha}-1\right)} \sum_{j=0}^{\infty} \psi_{j} \frac{t^{\Lambda_{r, j, \beta}}}{\Lambda_{r, j, \beta}} .
$$

Proof. The $r$-th incomplete moments $\Phi_{r}(t)$ are defined as

$$
\Phi_{r}(t)=\int_{0}^{t} x^{r} f(x) d x
$$

It is obtained for $X$ as

$\Phi_{r}(t)=\frac{\alpha \beta}{\left(g_{0}\right)^{\beta}\left(2^{\alpha}-1\right)} \sum_{j=0}^{\infty}\left(\begin{array}{c}\alpha-1 \\ j\end{array}\right) \frac{1}{\left(g_{0}\right)^{\beta(j+1)}} \int_{0}^{t} x^{r+\beta(j+1)-1} d x$.

Hence, $\Phi_{r}(t)$ of $X$ reduces to

$$
\Phi_{r}(t)=\frac{\alpha \beta}{\left(\mathrm{g}_{0}\right)^{\beta}\left(2^{\alpha}-1\right)} \sum_{j=0}^{\infty} \psi_{j} \frac{t^{\Lambda_{r, j, \beta}}}{\Lambda_{r, j, \beta}} .
$$

Corollary 3. The first incomplete moment is obtained by substituting $r=1$ in equation (33) as

$$
\Phi_{1}(t)=\frac{\alpha \beta}{\left(\mathrm{g}_{0}\right)^{\beta}\left(2^{\alpha}-1\right)} \sum_{j=0}^{\infty} \psi_{j} \frac{t^{\Lambda_{1, j, \beta}}}{\Lambda_{1, j, \beta}} .
$$

The residual life function is defined as

$$
R_{t}(x)=\frac{S(x+t)}{S(t)}
$$


Hence, the residual life function (RLF) and its associated $C D F$ of $X$ are given by

$$
R_{t(x)}=\frac{2^{\alpha}-\left(1+(x+t / g)^{\beta}\right)^{\alpha}}{2^{\alpha}-\left(1+\left(t /\left(g_{0}\right)\right)^{\beta}\right)^{\alpha}},
$$

and

$$
F_{R(t)}=\frac{\left(1+(x+t / g)^{\beta}\right)^{\alpha}-\left(1+(t / g)^{\beta}\right)^{\alpha}}{2^{\alpha}-\left(1+\left(t /\left(g_{0}\right)\right)^{\beta}\right)^{\alpha}}
$$

respectively.

Furthermore, the reversed $R L F$ is defined as $\bar{R}_{t}(x)=(S(x-t) / S(t))$. Hence, reversed $R L F$ and its associated CDF of $X$ take the forms:

$$
\begin{aligned}
\bar{R}_{t}(x) & =\frac{2^{\alpha}-\left(1+\left(x-t /\left(\mathrm{g}_{0}\right)\right)^{\beta}\right)^{\alpha}}{2^{\alpha}-\left(1+\left(t /\left(\mathrm{g}_{0}\right)\right)^{\beta}\right)^{\alpha}}, \\
F_{\bar{R}(t)} & =\frac{\left(1+\left(x-t /\left(\mathrm{g}_{0}\right)\right)^{\beta}\right)^{\alpha}-\left(1+\left(t /\left(\mathrm{g}_{0}\right)\right)^{\beta}\right)^{\alpha}}{2^{\alpha}-\left(1+\left(t /\left(\mathrm{g}_{0}\right)\right)^{\beta}\right)^{\alpha}} .
\end{aligned}
$$

The mean RLF is defined as $M R L=\left(1-\Phi_{1}(t) / S(t)-t\right)$. It is obtained for $X$ as

$$
M R L=\frac{1}{S(t)-t}\left(1-\frac{\alpha \beta}{\left(g_{0}\right)^{\beta}\left(2^{\alpha}-1\right)} \sum_{j=0}^{\infty} \psi_{j} \frac{t^{\Lambda_{1, j, \beta}}}{\Lambda_{1, j, \beta}}\right) .
$$

The mean inactivity time (MIT) is defined as MIT $=t-$ $\left(\Phi_{1}(t) / F(t)\right)$. It is obtained for $X$ as

$$
\operatorname{MIT}=t-\frac{\alpha \beta \sum_{j=0}^{\infty} \psi_{j}\left(t^{\Lambda_{1, j, \beta}} / \Lambda_{1, j, \beta}\right)}{\left(\mathrm{g}_{0}\right)^{\beta}\left(1+\left(x / \mathrm{g}_{0}\right)^{\beta}\right)^{\alpha}-1} .
$$

The strong mean inactivity time (SMIT) of a device is defined as SMIT $=t^{2}-\left(\Phi_{2}(t) / F(t)\right)$. It is obtained for $X$ as

$$
\operatorname{MIT}=t^{2}-\frac{\alpha \beta \sum_{j=0}^{\infty} \psi_{j}\left(t^{\Lambda_{1, j, \beta}} / \Lambda_{1, j, \beta}\right)}{\left(\mathrm{g}_{0}\right)^{\beta}\left(1+\left(x / \mathrm{g}_{0}\right)^{\beta}\right)^{\alpha}-1} .
$$

The mean past lifetime (MPL) of a device is defined as $M P L=x-\left(\int_{0}^{x} t f(t) d t / F(x)\right)$. It is obtained for $X$ as

$$
\operatorname{MPL}=\frac{x\left(\left(1+\left(x / \mathrm{g}_{0}\right)^{\beta}\right)^{\alpha}-1\right)-\left(2^{\alpha}-1\right)\left(\alpha \beta /\left(\mathrm{g}_{0}\right)^{\beta}\left(2^{\alpha}-1\right) \sum_{j=0}^{\infty} \psi_{j}\left(x^{\Lambda_{1, j, \beta} / \Lambda_{1, j, \beta}}\right)\right)}{\left(1+\left(x / \mathrm{g}_{0}\right)^{\beta}\right)^{\alpha}-1} .
$$

Furthermore, the Lorenz $(t)$, Bonferroni B $(t)$, and Zenga $Z(t)$ inequality curves have a significant role not only in the study of economics, the distribution of income, poverty, or wealth, but also they have a vital role in the fields of insurance, demography, medicine, and reliability engineering.

Theorem 5. If $X \sim \operatorname{EPF}(\alpha, \beta)$, then the Lorenz inequality curve of $X$ is

$$
L(t)=\frac{\sum_{j=0}^{\infty} \psi_{j}\left(t^{\Lambda_{1, j, \beta}} / \Lambda_{1, j, \beta}\right)}{\sum_{j=0}^{\infty} \psi_{j}\left(\left(g_{0}\right)^{\Lambda_{1, j, \beta}} / \Lambda_{1, j, \beta}\right)} .
$$

Proof. Lorenz inequality curve is defined as

$$
L(t)=\frac{\Phi_{1}(t)}{\mu_{1}^{\prime}} .
$$

It is obtained for $X$, using equations (17) and (34), as

$$
L(t)=\frac{\sum_{j=0}^{\infty} \psi_{j}\left(t^{\Lambda_{1, j, \beta}} / \Lambda_{1, j, \beta}\right)}{\sum_{j=0}^{\infty} \psi_{j}\left(\left(g_{0}\right)^{\Lambda_{1, j, \beta}} / \Lambda_{1, j, \beta}\right)} .
$$

Theorem 6. If $X \sim \operatorname{EPF}(\alpha, \beta)$, then the Bonferroni inequality curve of $X$ is as follows:

$$
B(t)=\frac{\left(2^{\alpha}-1\right) \sum_{j=0}^{\infty} \psi_{j}\left(t^{\Lambda_{1, j, \beta}} / \Lambda_{1, j, \beta}\right)}{\sum_{j=0}^{\infty} \psi_{j}\left(\left(\mathrm{~g}_{0}\right)^{\Lambda_{1, j, \beta}} / \Lambda_{1, j, \beta}\right)\left(\left(1+\left(x / \mathrm{g}_{0}\right)^{\beta}\right)^{\alpha}-1\right)}
$$

Proof. The Bonferroni inequality curve is defined as

$$
B(x)=\frac{L(t)}{F(x)}
$$

It is obtained for $X$, using $L(t)$ and the CDF of the EPF model, as

$$
B(t)=\frac{\left(2^{\alpha}-1\right) \sum_{j=0}^{\infty} \psi_{j}\left(t^{\Lambda_{1, j, \beta}} / \Lambda_{1, j, \beta}\right)}{\sum_{j=0}^{\infty} \psi_{j}\left(\left(g_{0}\right)^{\Lambda_{1, j, \beta}} / \Lambda_{1, j, \beta}\right)\left(\left(1+\left(x / g_{0}\right)^{\beta}\right)^{\alpha}-1\right)} .
$$

Theorem 7. If $X \sim \operatorname{EPF}(\alpha, \beta)$, then the Zenga inequality curve of $X$ reduces to

$$
Z(t)=\frac{\sum_{j=0}^{\infty} \psi_{j}\left(t^{\Lambda_{1, j, \beta}} / \Lambda_{1, j, \beta}\right)-t \sum_{j=0}^{\infty} \psi_{j}\left(\left(\mathrm{~g}_{0}\right)^{\Lambda_{1, j, \beta}} / \Lambda_{1, j, \beta}\right)}{t\left(\sum_{j=0}^{\infty} \psi_{j}\left(\left(\mathrm{~g}_{0}\right)^{\Lambda_{1, j, \beta}} / \Lambda_{1, j, \beta}\right)-\sum_{j=0}^{\infty} \psi_{j}\left(t^{\Lambda_{1, j, \beta} / \Lambda_{1, j, \beta}}\right)\right)} .
$$

Proof. Zenga inequality curve is defined as

$$
Z(t)=\frac{L(t)-t}{t(1-L(t))} .
$$

It is obtained for $X$ as 


$$
Z(t)=\frac{\sum_{j=0}^{\infty} \psi_{j}\left(t^{\Lambda_{1, j \beta}} / \Lambda_{1, j, \beta}\right)-t \sum_{j=0}^{\infty} \psi_{j}\left(\left(\mathrm{~g}_{0}\right)^{\Lambda_{1, j \beta}} / \Lambda_{1, j, \beta}\right)}{t\left(\sum_{j=0}^{\infty} \psi_{j}\left(\left(\mathrm{~g}_{0}\right)^{\Lambda_{1, j, \beta}} / \Lambda_{1, j, \beta}\right)-\sum_{j=0}^{\infty} \psi_{j}\left(t^{\Lambda_{1, j, \beta}} / \Lambda_{1, j, \beta}\right)\right)} .
$$

\section{Reliability Function and Associated Measures}

Probability distributions consider as a backbone for reliability engineering to analyze and predict the lifetime of a component/device. In this section, numerous notable reliability measures are discussed.

4.1. Survival Function. The survival function of $X$ takes the form:

$$
S(x)=\frac{2^{\alpha}-\left(1+\left(\left(x / g_{0}\right)\right)^{\beta}\right)^{\alpha}}{2^{\alpha}-1} .
$$

4.2. Hazard Rate Function. The HRF (in demography), failure rate function (in engineering), and sometimes it is called the force of mortality (in economics). The HRF of $X$ is

$$
h(x)=\frac{\alpha \beta x^{\beta-1}\left(1+\left(x / g_{0}\right)^{\beta}\right)^{\alpha-1}}{\left(g_{0}\right)^{\beta}\left(2^{\alpha}-\left(1+\left(x / g_{0}\right)^{\beta}\right)^{\alpha}\right)} .
$$

4.3. Mean Time between Failures. Mean time between failures $(\mathrm{MTBF})$ is defined as $(-t / \log (S(x)))$ Hence, it is obtained for $X$ as

$$
M T B F=\frac{-t}{\log \left(\left(2^{\alpha}-1\right)^{-1}\left(2^{\alpha}-\left(1+\left(x / g_{0}\right)^{\beta}\right)^{\alpha}\right)\right)} \text {. }
$$

4.4. Cumulative HRF. The cumulative HRF is defined as $h_{c}(x)=-\log (S(x))$. Hence, the cumulative HRF of $X$ has the form:

$$
h_{c}(x)=-\log \left(\frac{2^{\alpha}-\left(1+\left(x / g_{0}\right)^{\beta}\right)^{\alpha}}{2^{\alpha}-1}\right) .
$$

Figure 2 presents the different curves of the EPF of HRF for various choices of its parameters. We note that it possesses increasing U-shaped and bathtub shape curves for $\mathrm{g}_{0}=3$.

4.5. Reverse HRF. The reverse $\mathrm{HRF}$ is defined as $h_{r}(x)=$ $f(x) / S(x)$. It is obtained for $X$ as

$$
h_{r}(x)=\frac{\alpha \beta x^{\beta-1}\left(1+\left(x / g_{0}\right)^{\beta}\right)^{\alpha-1}}{\left(g_{0}\right)^{\beta}\left(2^{\alpha}-\left(1+\left(x / g_{0}\right)^{\beta}\right)^{\alpha}\right)} .
$$

4.6. Odds Ratio. The odds ratio is defined as $O(x)=F(x) / f(x)$. Hence, the odds ratio of $X$ is given by

$$
O(x)=\frac{\left(g_{0}\right)^{\beta}\left(\left(1+\left(x / g_{0}\right)^{\beta}\right)^{\alpha}-1\right)}{\alpha \beta x^{\beta-1}\left(1+\left(x / g_{0}\right)^{\beta}\right)^{\alpha-1}} .
$$

4.7. Mills Ratio. The mill's ratio is defined as $M(x)=S(x) / f(x)$. Hence, the mill's ratio of $X$ is

$$
M(x)=\frac{\left(g_{0}\right)^{\beta}\left(2^{\alpha}-\left(1+\left(x / g_{0}\right)^{\beta}\right)^{\alpha}\right)}{\alpha \beta x^{\beta-1}\left(1+\left(x / g_{0}\right)^{\beta}\right)^{\alpha-1}} .
$$

\section{Miscellaneous Measures}

\subsection{Quantile Function}

Theorem 8. If $X \sim \operatorname{EPF}(\alpha, \beta)$, then the $Q F$ of $X$ is given by

$$
\mathrm{Q} F=\mathrm{g}_{0}\left(\left(\left(2^{\alpha}-1\right) p+1\right)^{1 / \alpha}-1\right)^{1 / \beta} \text {. }
$$

Proof. The QF is defined by

$$
Q F=F^{-1}\left(x_{p}\right)=P\left(X \leq x_{p}\right), \quad p \in(0,1) .
$$

The $p$-th QF of $X$ is obtained, by inverting the CDF (7), as

$$
Q F=g_{0}\left(\left(\left(2^{\alpha}-1\right) p+1\right)^{(1 / \alpha)}-1\right)^{1 / \beta}
$$

Corollary 4. The $1^{\text {st }}$ quartile $\left(Q_{1}\right)$, median $\left(Q_{2}\right)$, and $3^{\text {rd }}$ quartile $\left(Q_{3}\right)$ of $X$ are obtained by substituting $p=0.25,0.5$, and 0.75 in (61), respectively. The analytical expressions are

$$
\begin{aligned}
& Q F_{\mathrm{Q} 1}=g_{0}\left(\left(\left(2^{\alpha}-1\right)(0.25)+1\right)^{(1 / \alpha)}-1\right)^{1 / \beta}, \\
& Q F_{\mathrm{Q} 2}=g_{0}\left(\left(\left(2^{\alpha}-1\right)(0.50)+1\right)^{(1 / \alpha)}-1\right)^{1 / \beta},
\end{aligned}
$$

and

$$
Q F_{Q 3}=g_{0}\left(\left(\left(2^{\alpha}-1\right)(0.75)+1\right)^{(1 / \alpha)}-1\right)^{1 / \beta},
$$

respectively.

5.2. Skewness and Kurtosis. Bowley's [41] and Moors's [42] coefficients of skewness and kurtosis can be calculated by the following two equations:

$$
\begin{aligned}
B_{s k} & =\frac{Q_{0.75}+Q_{0.25}-2 Q_{0.50}}{Q_{0.75}-Q_{0.25}}, \\
M_{k r} & =\frac{Q_{0.375}-Q_{0.125}-Q_{0.625}+Q_{0.875}}{Q_{0.75}-Q_{0.25}} .
\end{aligned}
$$

Quartiles and octiles based on these descriptive measures provide more robust estimates than the traditional skewness and kurtosis measures. We note that these measures are almost less reactive to outliers and work more effectively for the distributions, deficient in moments. Figure 3 illustrates 

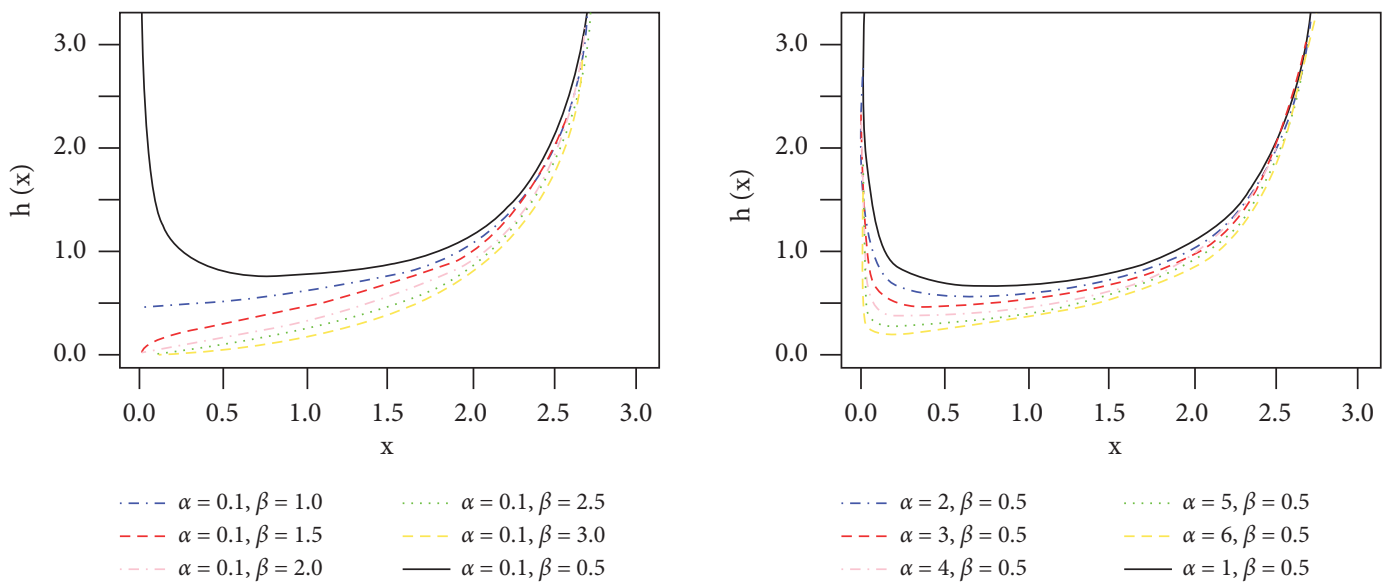

$\begin{aligned}-\alpha & =3, \beta=0.5 \\ -\alpha & =4, \beta=0.5\end{aligned}$

$\alpha=1, \beta=0.5$

FIgURE 2: Some curves of the HRF for the EPF distribution.
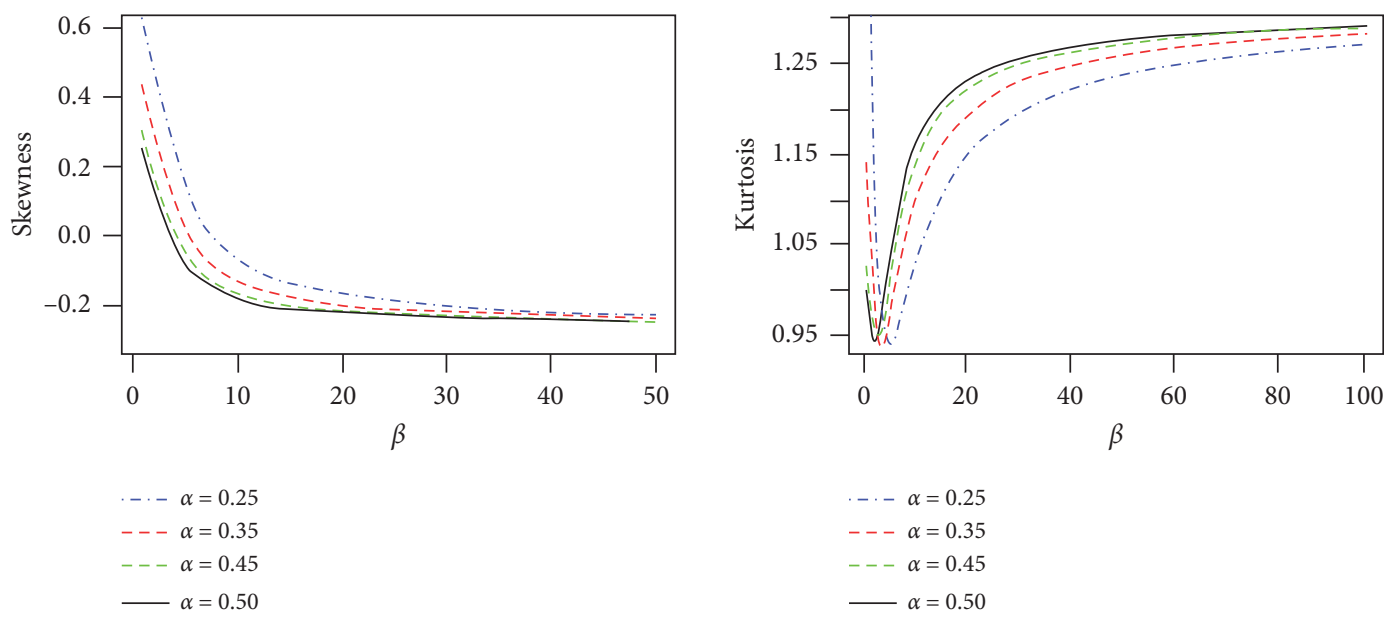

Figure 3: Skewness (left panel) and Kurtosis (right panel) curves for EPF distribution is

the skewness and kurtosis curves for the EPF distribution. We note that skewness and kurtosis are expressed as a function of $\beta$. Figure 3 illustrates a positive to negative trend of skewness, and an increasing trend in kurtosis can be observed with the increase of $\alpha$.

$$
I_{\delta}(X)=\frac{1}{1-\delta} \log \int_{0}^{g_{o}} f^{\delta}(x) d x, \delta>0 \text { an } d \delta \neq 1 .
$$

5.3. Entropy Measures. Kurtosis and entropy measures have the same role in comparing the shapes and tail weights of various density functions. The entropy of a random variable $X$ is defined as a measure of uncertainty.

In this section, we have developed numerous wellknown entropy measures including Rényi [43], Havrda and Charvat [44], and Mathai and Haubold [45]. For more details, see some promising work of Basit et al. [46], Dey et al. [47], and Ijaz et al. [48].
Theorem 9. If $X \sim \operatorname{EPF}(\alpha, \beta)$, then the Rényi entropy of $X$ is

$$
\begin{gathered}
\frac{1}{1-\delta} \log \left(\frac{\alpha \beta}{\left(2^{\alpha}-1\right)}\right) \sum_{i=0}^{\delta}\left(\begin{array}{c}
\delta(\alpha-1) \\
i
\end{array}\right) g_{0}^{-\beta(i+1)} \\
\frac{\left(g_{o}\right)^{\beta i+\delta(\beta-1)+1}}{\beta i+\delta(\beta-1)+1} ; \delta>0 \text { an } d \delta \neq 1 .
\end{gathered}
$$

Proof. The Rényi entropy for $X$ is defined by Using Equation (10), we can write

$$
f^{\delta}(x)=\left(\frac{\alpha \beta}{\left(g_{0}\right)^{\beta}\left(2^{\alpha}-1\right)}\right)^{\delta} x^{\delta(\beta-1)}\left(1+\left(\frac{x}{g_{0}}\right)^{\beta}\right)^{\delta(\alpha-1)} .
$$

Then, integration $f^{\delta}(x)$ gives 


$$
\begin{aligned}
& \int_{0}^{g_{0}} f^{\delta}(x) d x=\left(\frac{\alpha \beta}{\left(2^{\alpha}-1\right)}\right)^{\delta} \sum_{i=0}^{\infty}\left(\begin{array}{c}
\delta(\alpha-1) \\
i
\end{array}\right)\left(g_{o}\right)^{-\beta(i+1)} \\
& \frac{\left(g_{o}\right)^{\beta i+\delta(\beta-1)+1}}{\beta i+\delta(\beta-1)+1} .
\end{aligned}
$$

Hence, the Rényi entropy reduces to

$$
\begin{aligned}
I_{\delta}(X)= & \frac{1}{1-\delta} \log \left(\frac{\alpha \beta}{\left(2^{\alpha}-1\right)}\right) \sum_{i=0}^{\delta}\left(\begin{array}{c}
\delta(\alpha-1) \\
i
\end{array}\right) g_{0}^{-\beta(i+1)} \\
& \frac{\left(g_{o}\right)^{\beta i+\delta(\beta-1)+1}}{\beta i+\delta(\beta-1)+1} .
\end{aligned}
$$

The expression developed in (68) is quite helpful in the further computation of entropy measures of Havrda and Charvat, and Mathai and Haubold. The final expressions of Havrda and Charvat, and Mathai and Haubold entropy measures are presented in Table 2.

Table 3 presents the results of Rényi, Havrda and Charvat, and Mathai and Haubold entropy measures for some choices of model parameters for $\left(\mathrm{g}_{\mathrm{o}}=3\right)$, Set-I $(\alpha=1.1, \beta=2.1)$, Set -II $(\alpha=2.1, \beta=2.5)$, Set $\quad$-III $(\alpha=0.1, \beta=0.6)$, and Set-IV $(\alpha=0.01, \beta=1.1)$.

A wide range of positive and negative values of entropy measures makes the EPF distribution more flexible and versatile.

5.4. Distribution of Order Statistics. Let $X_{1}, \ldots, X_{n}$ be a random sample of size $n$ and their corresponding order statistics (OS) $X_{(1)}<\ldots<X_{(n)}$ from the EPF distribution. The PDF of the $i$-th OS is $f_{(i: n)}(x)=1 / B(i, n-i+1) !(F(x))^{i-1}(1-F(x))^{n-i} f(x)$, $i=1,2,3, \ldots, n$.

The $i$-th OS density is obtained by incorporating Equations (6) and (8) in the last equation.

$$
\begin{aligned}
f_{(i: n)}(x)= & \frac{1}{B(i, n-i+1) !}\left(\frac{\left(1+\left(x / \mathrm{g}_{0}\right)^{\beta}\right)^{\alpha}-1}{2^{\alpha}-1}\right)^{i-1} \\
& \left(\frac{2^{\alpha}-\left(1+\left(x / \mathrm{g}_{0}\right)^{\beta}\right)^{\alpha}}{2^{\alpha}-1}\right)^{n-i} \\
& \frac{\alpha \beta}{\left(\mathrm{g}_{0}\right)^{\beta}\left(2^{\alpha}-1\right)} x^{\beta-1}\left(1+\left(x / \mathrm{g}_{0}\right)^{\beta}\right)^{\alpha-1} .
\end{aligned}
$$

The minimum and maximum OS densities are obtained, respectively, by substituting $i=1, n$ in (70).

The $i$-th OS CDF is defined by

$$
G(x)=\sum_{r=i}^{n}\left(\begin{array}{l}
n \\
r
\end{array}\right)(1-F(x))^{n-r} F^{r}(x) .
$$

The $i$-th OS CDF of the EPF distribution reduces to

$$
\begin{aligned}
G(x)= & \sum_{r=1}^{n}\left(\begin{array}{c}
n \\
r
\end{array}\right)\left(\frac{\left(1+\left(x / g_{0}\right)^{\beta}\right)^{\alpha}-1}{2^{\alpha}-1}\right)^{r} \\
& \left(\frac{\left(1+\left(x / g_{0}\right)^{\beta}\right)^{\alpha}-1}{2^{\alpha}-1}\right)^{n-r} .
\end{aligned}
$$

The median $i$-th OS PDF is

$$
f_{(m+1: n)}(x)=\frac{(2 m+1) !}{(m !)^{2}} f(x)(F(x))^{m}(1-F(x))^{m} .
$$

The $X_{m+1}$ median OS PDF of the EPF distribution has the form:

$$
\begin{aligned}
f_{(m+1: n)}(x)= & \frac{(2 m+1) !}{(m !)^{2}} \frac{\alpha \beta}{\left(\mathrm{g}_{0}\right)^{\beta}\left(2^{\alpha}-1\right)} x^{\beta-1}\left(1+\left(\frac{x}{\mathrm{~g}_{0}}\right)^{\beta}\right)^{\alpha-1} \\
& \left(\frac{\left(1+\left(x / \mathrm{g}_{0}\right)^{\beta}\right)^{\alpha}-1}{2^{\alpha}-1}\right)^{m}\left(\frac{2^{\alpha}-\left(1+\left(x / \mathrm{g}_{0}\right)^{\beta}\right)^{\alpha}}{2^{\alpha}-1}\right)^{m} .
\end{aligned}
$$

The $i$-th and $j$-th OS joint distribution is defined by

$$
\begin{aligned}
f\left(x_{i}, x_{j}\right)= & C\left(F\left(x_{i}\right)\right)^{i-1}\left(F\left(x_{j}\right)-F\left(x_{i}\right)\right)^{j-i-1} \\
& \left(1-F\left(x_{j}\right)\right)^{n-j} f\left(x_{i}\right) f\left(x_{j}\right) .
\end{aligned}
$$

For the $i$-th and $j$-th OS joint distribution of the EPF model is as follows:

$$
\begin{aligned}
f\left(x_{i}, x_{j}\right)= & \frac{C(\alpha \beta)^{2}\left(x_{i} x_{j}\right)^{\beta-1}}{\left(\mathrm{~g}_{0}\right)^{2 \beta}\left(2^{\alpha}-1\right)^{2}}\left[\left(1+\left(\frac{x_{i}}{\mathrm{~g}_{0}}\right)^{\beta}\right)\left(1+\left(\frac{x_{j}}{\mathrm{~g}_{0}}\right)^{\beta}\right)\right]^{\alpha-1} \\
& {\left[\frac{\left(1+\left(x / \mathrm{g}_{0}\right)^{\beta}\right)^{\alpha}-1}{2^{\alpha}-1}\right]^{i-1}\left[1-\frac{\left(1+\left(x / \mathrm{g}_{0}\right)^{\beta}\right)^{\alpha}-1}{2^{\alpha}-1}\right]^{n-j} } \\
& {\left[\frac{\left(1+\left(x_{j} / \mathrm{g}_{0}\right)^{\beta}\right)^{\alpha}-\left(1+\left(x_{i} / \mathrm{g}_{0}\right)^{\beta}\right)^{\alpha}}{2^{\alpha}-1}\right]^{j-i-1} . }
\end{aligned}
$$

5.5. Bivariate and Multivariate Extensions. In this section, we develop the bivariate and multivariate extensions for the EPF distribution by following the Morgenstern family and the Clayton family

The CDF of the bivariate EPF distribution followed by the Clayton family for the random vector $(X, Y)$ is

$F\left(V_{1}, V_{2}\right)=\left(1+\eta\left(1-Z_{1}\left(v_{1}\right)\right)\left(1-Z_{2}\left(v_{2}\right)\right)\right) Z_{1}\left(v_{1}\right) Z_{2}\left(v_{2}\right)$,

where $|\eta| \leq 1, \quad Z_{1}\left(v_{1}\right)=\left(\left(1+\left(x_{1} / g_{0}\right)^{\beta_{1}}\right)^{\alpha_{1}}-1 / 2^{\alpha_{1}}-1\right)$ and $Z_{2}\left(v_{2}\right)=\left(\left(1+\left(x_{2} / g_{0}\right)^{\beta_{2}}\right)^{\alpha_{2}}-1 / 2^{\alpha_{2}}-1\right)$.

The CDF of the bivariate EPF distribution followed by the Morgenstern family for the random vector $\left(V_{1}, V_{2}\right)$ is defined as 
TABle 2: The final expressions for Havrda and Charvat, and Mathai and Haubold entropy measures.

\begin{tabular}{lcc}
\hline Entropy/Support & Measure & Expression \\
\hline $\begin{array}{l}\text { Havrda and Charvat } \\
\omega>0, \omega \neq 1\end{array}$ & $(1 / 1-\omega)\left(\int_{0}^{\mathrm{g}_{o}} f^{\omega}(x) d x-1\right)$ & $\left.\frac{1}{1-\omega}\left(\left(\frac{\alpha \beta}{\left(2^{\alpha}-1\right)}\right)^{\omega} \sum_{i=0}^{\infty}\left(\begin{array}{c}\omega(\alpha-1) \\
i\end{array}\right) \mathrm{g}_{0}^{-\beta(i+1)} \times \frac{\left(\mathrm{g}_{0}\right)^{\beta i+\omega(\beta-1)+1}}{\beta i+\omega(\beta-1)+1}\right)-1\right)$ \\
$\begin{array}{l}\text { Mathai and Haubold } \\
\vartheta>0, \vartheta \neq 1\end{array}$ & $(1 / \vartheta-1)\left(\int_{0}^{\mathrm{g}_{o}} f^{2-\vartheta}(x) d x-1\right)$ & $\left.\frac{1}{9-1}\left(\left(\frac{\alpha \beta}{\left(2^{\alpha}-1\right)}\right)^{2-\vartheta} \sum_{i=0}^{\infty}\left(\begin{array}{c}(2-\vartheta)(\alpha-1) \\
i\end{array}\right) g_{0}^{-\beta(i+1)} \times \frac{\left(g_{o}\right)^{\beta i+(2-\vartheta)(\beta-1)+1}}{\beta i+(2-\vartheta)(\beta-1)+1}\right)-1\right)$
\end{tabular}

Table 3: Numerical analysis for Rényi, Havrda and Charvat, and Mathai and Haubold entropy measures.

\begin{tabular}{|c|c|c|c|c|c|}
\hline Entropy & Int. & Set -I & Set -II & Set -III & Set-IV \\
\hline \multirow{4}{*}{ Rényi } & $\delta=1.1$ & 48.5073 & 45.5568 & 42.9999 & 36.4934 \\
\hline & $\delta=1.5$ & 13.2292 & 12.4246 & 11.7272 & 9.9527 \\
\hline & $\delta=1.7$ & 10.7094 & 10.0580 & 9.4934 & 8.0570 \\
\hline & $\delta=1.9$ & 9.3094 & 8.7432 & 8.2525 & 7.0038 \\
\hline \multirow{4}{*}{ Havrda and Charvat } & $\omega=1.1$ & 20.8214 & 20.9130 & 20.7450 & 21.0333 \\
\hline & $\omega=1.5$ & 4.6657 & 4.7472 & 4.4961 & 4.8391 \\
\hline & $\omega=1.7$ & 3.4637 & 3.5389 & 3.2307 & 3.6180 \\
\hline & $\omega=1.9$ & 2.7785 & 2.8473 & 2.4510 & 2.9149 \\
\hline \multirow{4}{*}{ Mathai and Haubold } & $コ=1.1$ & -19.0736 & -18.9800 & -19.1095 & -18.8459 \\
\hline & $\beth=1.5$ & -2.7702 & -2.6883 & -2.7356 & -2.5421 \\
\hline & $\beth=1.7$ & -1.3975 & -1.3360 & -1.3444 & -1.2080 \\
\hline & $\beth=1.9$ & -0.4388 & -0.4138 & -0.4027 & -0.3487 \\
\hline
\end{tabular}

$C(x, y)=\left(x^{-\left(\tau_{1}+\tau_{2}\right)}+y^{-\left(\tau_{1}+\tau_{2}\right)}-1\right)^{-1 /\left(\tau_{1}+\tau_{2}\right)} ; \tau_{1}+\tau_{2} \geq 0$.
Let $v_{1} \sim \operatorname{EPF}\left(\alpha_{1}, \beta_{1}\right)$, and $v_{2} \sim \operatorname{EPF}\left(\alpha_{2}, \beta_{2}\right)$. Then, we set $x=Z_{1}\left(v_{1}\right)=\left(\left(1+\left(x_{1} / g_{0}\right)^{\beta_{1}}\right)^{\alpha_{1}}-1 / 2^{\alpha_{1}}-1\right)$, and $y=Z_{2}$ $\left(v_{2}\right)=\left(\left(1+\left(x_{2} / g_{0}\right)^{\beta_{2}}\right)^{\alpha_{2}}-1 / 2^{\alpha_{2}}-1\right)$.

The CDF of the bivariate EPF distribution followed by the Clayton family for the random vector $\left(V_{1}, V_{2}\right)$ is

$$
G\left(v_{1}, v_{2}\right)=\left(\left(\frac{\left(1+\left(x_{1} / g_{0}\right)^{\beta_{1}}\right)^{\alpha_{1}}-1}{2^{\alpha_{1}}-1}\right)^{\left(\tau_{1}+\tau_{2}\right)}+\left(\frac{\left(1+\left(x_{2} / g_{0}\right)^{\beta_{2}}\right)^{\alpha_{2}}-1}{2^{\alpha_{2}}-1}\right)^{\left(\tau_{1}+\tau_{2}\right)}-1\right)^{-\left(1 /\left(\tau_{1}+\tau_{2}\right)\right)}
$$

A simple $n$-dimensional extension of the last version for EPF distribution has the form:

$$
H\left(x_{1}, x_{2}, x_{3}, \ldots, x_{n}\right)=\left(\sum_{j=1}^{n}\left(\left(1 \frac{\left(1+\left(x_{1} / g_{0}\right)^{\beta_{j}}\right)^{\alpha_{j}}-1}{2^{\alpha_{j}}-1}\right)^{\left(\tau_{1}+\tau_{2}\right)}\right)+1-n\right)^{-\left(1 /\left(\tau_{1}+\tau_{2}\right)\right)} .
$$

\section{Statistical Inference}

In this section, we discuss six estimation techniques for the EPF parameters as follows: maximum likelihood estimators (MLEs), maximum product of spacing estimators (MPSEs), percentile estimators (PCEs), Cramér von-Mise distance estimators (CVMEs), Anderson-Darling estimators (ADEs), and right-tail Anderson-Darling estimators (RTADEs).
6.1. Maximum Likelihood Estimators. Let $x_{1}, \ldots, x_{n}$ be a random sample of size $n$ from the EPF model; then, the likelihood function of $L(\phi)=\prod_{j=1}^{n} f\left(x_{j}\right)$ is given by

$L(\phi)=\left(\frac{\alpha \beta}{\left(\mathrm{g}_{0}\right)\left(2^{\alpha}-1\right)}\right)^{n} \prod_{j=1}^{n}\left(\frac{x_{j}}{\mathrm{~g}_{0}}\right)^{\beta-1} \prod_{j=1}^{n}\left(1+\left(\frac{x_{j}}{\mathrm{~g}_{0}}\right)^{\beta}\right)^{\alpha-1}$.

The $\log L(\phi)=l(\phi)$ takes the form: 


$$
\begin{aligned}
l(\phi)= & n \log (\alpha)+n \log (\beta)-n \log \left(\mathrm{g}_{0}\right)-n \log \left(2^{\alpha}-1\right) \\
& +(\beta-1) \sum_{j=1}^{n} \log \left(\frac{x_{j}}{\mathrm{~g}_{0}}\right)+(\alpha-1) \sum_{j=1}^{n} \log \left(1+\left(\frac{x_{j}}{\mathrm{~g}_{0}}\right)^{\beta}\right) .
\end{aligned}
$$

Let $y_{j}=\left(x_{j} / g_{0}\right)$. The partial derivatives for the parameters $\alpha$ and $\beta$ are

$$
\frac{\partial l(\phi)}{\partial \alpha}=\frac{n}{\alpha}-\frac{n\left(2^{\alpha} \log 2\right)}{2^{\alpha}-1}+\sum_{j=1}^{n} \log \left(1+y_{j}^{\beta}\right),
$$

and

$$
\frac{\partial l(\phi)}{\partial \beta}=\frac{n}{\beta}+\sum_{j=1}^{n} \log y_{j}+(\alpha-1) \sum_{j=1}^{n} \frac{y^{\beta} \log y_{j}}{\left(1+y_{j}^{\beta}\right)} .
$$

The maximum likelihood estimates $(\widehat{\phi}=\widehat{\alpha,} \widehat{\beta})$ of the EPF parameters can be obtained by maximizing (82) or by solving the above nonlinear equations simultaneously. These nonlinear equations although do not provide an analytical solution for the MLEs and the optimum values of $\alpha$, and $\beta$. Consequently, the Newton-Raphson type algorithm is an appropriate choice to obtain the MLEs.

6.2. Maximum Product of Spacing Estimators. The MPSEs are alternatives to the MLEs, and they are introduced by Cheng and Amin $[49,50]$. Let $x_{1}, \ldots, x_{n}$ be a uniform spacing of a random sample taken from the EPF distribution is defined by $D_{j}=F\left(x_{j: n}\right)-F\left(x_{(j-1: n)}\right)$, $j=1,2,3, \ldots, n$, where $D_{j}$ denotes the uniform spacing, $x_{j}$ is $j$-th order statistics, and $\left(x_{0: n}\right)=0, F\left(x_{n+1: n}\right)=1$, and $\sum_{j=1}^{n+1} D_{j}=1$, and the MPSEs of the EPF parameters are obtained by maximizing

$$
P(\alpha, \beta)=\frac{1}{n+1} \sum_{j=1}^{n+1} \log D_{j}
$$

These estimators can also be obtained by solving

$$
\frac{1}{n+1} \sum_{j=1}^{n+1} \frac{1}{D_{j}}\left(\nabla_{t}\left(x_{j: n}\right)-\nabla_{t}\left(x_{(j-1: n)}\right)\right)=0,
$$

where

$$
\begin{aligned}
& \nabla_{1}\left(x_{j: n}\right)=\frac{\partial}{\partial \alpha} F\left(x_{j: n}\right), \\
& \nabla_{2}\left(x_{j: n}\right)=\frac{\partial}{\partial \beta} F\left(x_{j: n}\right) .
\end{aligned}
$$

6.3. Percentile Estimators. The percentile method was introduced by Kao [51]. This method allows estimating the unknown parameters if the distribution function has a closed-form expression. Suppose $u_{j}=j /(n+1)$ be an unbiased estimator of $F\left(x_{j: n}\right)$. The PCEs of the EPF parameters are obtained by minimizing

$$
P(\alpha, \beta)=\sum_{j=1}^{n}\left(x_{j: n}-\mathrm{g}_{0}\left(\left(\left(2^{\alpha}-1\right) u_{j}+1\right)^{(1 / \alpha)}-1\right)^{(1 / \beta)}\right)^{2},
$$

with respect to $\alpha$ and $\beta$, respectively.

6.4. Cramér von-Mise Estimators. Cramér [52] and Von Mises [53] introduced a relatively less-biased minimum distance estimator called the CVMEs. It can be obtained by making a difference between the estimates of the CDF and empirical CDF. The CVMEs of the EPF parameters are obtained by minimizing

$$
C(\alpha, \beta)=\frac{1}{12 n}+\sum_{j=1}^{n}\left(F\left(x_{j: n}\right)-\frac{2 j-1}{2 n}\right),
$$

with respect to $\alpha$ and $\beta$. Furthermore, the CVMEs follow by solving the nonlinear equations as

$$
C(\alpha, \beta)=\frac{1}{12 n}+\sum_{j=1}^{n}\left(F\left(x_{j: n}\right)-\frac{2 j-1}{2 n}\right) \nabla_{t}\left(x_{j: n}\right)=0,
$$

where $\nabla_{t}\left(x_{j: n}\right)=0$ for $t=1,2$ is defined by (87).

6.5. Anderson-Darling and Right-Tail Anderson-Darling Estimators. Another type of minimum distance estimators is the ADEs. The ADEs of the EPF parameters are obtained by minimizing

$A(\alpha, \beta)=-n-\frac{1}{n}+\sum_{j=1}^{n}(2 j-1)\left(\log \left(F\left(x_{j: n}\right)\right)+\log \left(S\left(x_{j: n}\right)\right)\right)$,

with respect to $\alpha$ and $\beta$, respectively. The ADEs are also obtained by solving the following nonlinear equation as

$$
\sum_{j=1}^{n}(2 j-1)\left(\frac{\nabla_{t}\left(x_{j: n}\right)}{F\left(x_{j: n}\right)}+\frac{\nabla_{t}\left(x_{(n+1-j: n)}\right)}{S\left(x_{n+1-j: n}\right)}\right),
$$

where $\nabla_{t}\left(x_{j: n}\right)=0$ (for $\left.t=1,2\right)$ is defined by (87).

The RTADEs of the EPF parameters can be determined by minimizing

$$
A(\alpha, \beta)=\frac{n}{2}-2+\sum_{j=1}^{n}\left(F\left(x_{j: n}\right)\right)-\frac{1}{n} \sum_{j=1}^{n}(2 j-1) \log \left(S\left(x_{j: n}\right)\right),
$$

with respect to $\alpha$ and $\beta$.

\section{Simulation Experiment}

In this section, we perform a simulation study to assess the behavior of different estimators in estimating the EPF parameters. We generate $N=1,000$ replicates using (61) for several sample sizes $n=25,50$, and 100 with different combinations of the parameters. We calculate the average values of the estimates (AEs): 
TABle 4: The AEs and MSEs for $(\alpha=1.5 \text { and } \beta=2.0)^{T}$.

\begin{tabular}{|c|c|c|c|c|c|c|c|c|}
\hline$n$ & Par. & Est. & MLEs & MPSEs & PCEs & CVMEs & ADEs & RTADEs \\
\hline \multirow{2}{*}{25} & $\widehat{\alpha}$ & $\begin{array}{c}\mathrm{AE} \\
\mathrm{MSE}\end{array}$ & $1.5430(0.0808)$ & $1.5267(0.0701)$ & $1.5072(0.0624)$ & $2.1794(0.0910)$ & $1.5603(0.0910)$ & $1.5871(0.1243)$ \\
\hline & $\widehat{\beta}$ & $\begin{array}{c}\text { AE } \\
\text { MSE }\end{array}$ & $2.0408(0.3065)$ & $2.0101(0.2620)$ & $2.7331(2.0871)$ & $2.2208(0.2764)$ & $2.0208(0.2764)$ & $2.0156(0.2693)$ \\
\hline \multirow{2}{*}{50} & $\widehat{\alpha}$ & $\begin{array}{c}\mathrm{AE} \\
\mathrm{MSE}\end{array}$ & $1.5380(0.0658)$ & $1.5225(0.0631)$ & $1.5051(0.0615)$ & $1.7521(0.0739)$ & $1.5474(0.0704)$ & $1.6042(0.0988)$ \\
\hline & $\widehat{\beta}$ & $\begin{array}{c}\text { AE } \\
\text { MSE }\end{array}$ & $2.0080(0.2592)$ & $2.0020(0.2522)$ & $2.8602(2.2141)$ & $2.1503(0.2278)$ & $2.0027(0.2530)$ & $2.0026(0.2529)$ \\
\hline \multirow{2}{*}{100} & $\widehat{\alpha}$ & $\begin{array}{c}\text { AE } \\
\text { MSE }\end{array}$ & $1.5048(0.0609)$ & $1.5037(0.0610)$ & $1.5001(0.0575)$ & $1.5407(0.0086)$ & $1.5053(0.0610)$ & $1.5179(0.0597)$ \\
\hline & $\widehat{\beta}$ & $\begin{array}{c}\mathrm{AE} \\
\mathrm{MSE}\end{array}$ & $2.0009(0.2509)$ & $2.0005(0.2505)$ & $2.6984(1.6397)$ & $2.0602(0.0541)$ & $2.0006(0.2506)$ & $2.0011(0.2511)$ \\
\hline
\end{tabular}

TABle 5: The AEs and MSEs for $(\alpha=2.5 \text { and } \beta=1.5)^{T}$.

\begin{tabular}{|c|c|c|c|c|c|c|c|c|}
\hline$n$ & Par. & Est. & MLEs & MPSEs & PCEs & CVMEs & ADEs & RTADEs \\
\hline \multirow{2}{*}{25} & $\widehat{\alpha}$ & $\begin{array}{c}\mathrm{AE} \\
\mathrm{MSE}\end{array}$ & $2.5273(0.6168)$ & $2.5153(0.5912)$ & $2.5001(0.5627)$ & $2.7881(1.6927)$ & $2.5425(0.6557)$ & $2.5900(0.8361)$ \\
\hline & $\widehat{\beta}$ & $\begin{array}{c}\text { AE } \\
\text { MSE }\end{array}$ & $1.5308(0.0105)$ & $1.5100(0.0024)$ & $2.1981(0.8746)$ & $1.8852(1.3466)$ & $1.5182(0.0051)$ & $1.5156(0.0031)$ \\
\hline \multirow{2}{*}{50} & $\widehat{\alpha}$ & $\begin{array}{c}\mathrm{AE} \\
\mathrm{MSE}\end{array}$ & $2.5270(0.6001)$ & $2.5394(0.5378)$ & $2.5001(0.5627)$ & $2.6770(1.2651)$ & $2.5448(0.6367)$ & $2.5675(0.7333)$ \\
\hline & $\widehat{\beta}$ & $\begin{array}{c}\text { AE } \\
\text { MSE }\end{array}$ & $1.5188(0.0055)$ & $1.5047(0.0008)$ & $2.2336(0.7808)$ & $1.7453(0.8573)$ & $1.5088(0.0024)$ & $1.5088(0.0025)$ \\
\hline \multirow{2}{*}{100} & $\widehat{\alpha}$ & $\begin{array}{c}\text { AE } \\
\text { MSE }\end{array}$ & $2.5249(0.5734)$ & $2.5197(0.4719)$ & $2.5000(0.5626)$ & $2.5033(0.5659)$ & $2.5241(0.6150)$ & $2.5281(0.6267)$ \\
\hline & $\widehat{\beta}$ & $\begin{array}{c}\text { AE } \\
\text { MSE }\end{array}$ & $1.5032(0.0001)$ & $1.5006(0.0000)$ & $2.2794(0.7528)$ & $1.5003(0.0000)$ & $1.5018(0.0001)$ & $1.5018(0.0001)$ \\
\hline
\end{tabular}

$$
A E(\widehat{\varphi})=\frac{1}{N} \sum_{i=1}^{N} \widehat{\varphi}
$$

and the mean square errors (MSEs):

$$
\operatorname{MSE}(\widehat{\varphi})=\frac{1}{N} \sum_{i=1}^{N}\left(\widehat{\varphi}_{i}-\varphi\right)^{2},
$$

where $\varphi=(\alpha, \beta)$.

The selection of the best estimation method will be made having a minimum value of MSEs. The $R$ software (DEoptim package) is adopted to obtain the simulation results. The results of AEs and MSEs (in parenthesis) for the MLEs, MPSEs, PCEs, CVMEs, ADEs, and RTADEs are presented in Tables 4-7. It is noted that the AEs tend to their true parameter values, and the MSEs decrease with the increase in the sample size. This evidence is enough to favor that the estimators are unbiased asymptotically. All estimation methods perform efficiently for different combinations.

\section{Application in Automobile Engineering}

In this section, we analyze automobile engineering data. The data represent the time to failure $\left(10^{3} \mathrm{~h}\right)$ of turbocharger of one type of engine discussed by $\mathrm{Xu}$ et al. [54]. The observations are as follows: 1.6, 2.0, 2.6, 3.0, 3.5, 3.9, 4.5, 4.6, 4.8, 5.0, 5.1, 5.3, 5.4, 5.6, 5.8, 6.0, 6.0, 6.1, 6.3, 6.5, 6.5, 6.7, 7.0, 7.1, 7.3, 7.3, 7.3, 7.7, 7.7, 7.8, 7.9, 8.0, 8.1, 8.3, 8.4, 8.4, 8.5, 8.7, 8.8, 9.0. This dataset is analyzed by Afify et al. [55] and Nassar et al. [56].

The EPF distribution is compared with some wellknown competitors, namely, the Weibull power function (W-PF) and the zero-truncated Poisson power function (ZTP-PF). Their CDFs are presented in Table 8. The criterion -log-likelihood (-LL), Akaike information criterion (AIC), along with the goodness-of-fit statistics such as Kolmogorov -Smirnov (KS) with its $p$-value, are adopted. Some descriptive statistics are presented in Table 9. Table 10 presents the estimates and standard errors (SEs) alongside the goodness-of-fit statistics as well. Based on the results in Table 10, we conclude that the EPF distribution provide better fit among all well-established competitors.

Furthermore, the empirical fitted density (i), estimated CDF (ii), probability-probability (PP) (iii), Kaplan-Meier survival (iv), along with the TTT plot (v), and box plot (vi) are illustrated in Figure 4, respectively. All the estimates and numerical results are calculated using the statistical software $R$, package adequacy model developed by Rafael et al. [57]. 
TABle 6: The AEs and MSEs for $(\alpha=0.8 \text { and } \beta=0.5)^{T}$.

\begin{tabular}{|c|c|c|c|c|c|c|c|c|}
\hline$n$ & Par. & Est. & MLEs & MPSEs & PCEs & CVMEs & ADEs & RTADEs \\
\hline \multirow{2}{*}{25} & $\widehat{\alpha}$ & $\begin{array}{c}\mathrm{AE} \\
\mathrm{MSE}\end{array}$ & $0.8861(0.5333)$ & $0.8802(0.5386)$ & $0.8022(0.3627)$ & $0.8902(0.6356)$ & $0.8968(0.5663)$ & $0.9439(0.6981)$ \\
\hline & $\widehat{\beta}$ & $\begin{array}{c}\text { AE } \\
\text { MSE }\end{array}$ & $0.5156(0.0019)$ & $0.5026(0.0003)$ & $0.5355(0.0107)$ & $0.5325(0.0015)$ & $0.5105(0.0018)$ & $0.5125(0.0021)$ \\
\hline \multirow{2}{*}{50} & $\widehat{\alpha}$ & $\begin{array}{c}\text { AE } \\
\text { MSE }\end{array}$ & $0.8229(0.4093)$ & $0.8267(0.4108)$ & $0.8026(0.3531)$ & $0.8377(0.5548)$ & $0.8238(0.4121)$ & $0.8348(0.4369)$ \\
\hline & $\widehat{\beta}$ & $\begin{array}{c}\text { AE } \\
\text { MSE }\end{array}$ & $0.5083(0.0007)$ & $0.5036(0.0002)$ & $0.5074(0.0016)$ & $0.5234(0.0007)$ & $0.5049(0.0005)$ & $0.5039(0.0004)$ \\
\hline \multirow{2}{*}{100} & $\widehat{\alpha}$ & $\begin{array}{c}\mathrm{AE} \\
\mathrm{MSE}\end{array}$ & $0.8076(0.3702)$ & $0.8061(0.3677)$ & $0.8023(0.3227)$ & $0.8089(0.4527)$ & $0.8089(0.3721)$ & $0.8243(0.3958)$ \\
\hline & $\widehat{\beta}$ & $\begin{array}{c}\text { AE } \\
\text { MSE }\end{array}$ & $0.5021(0.0000)$ & $0.5008(0.0000)$ & $0.5006(0.0000)$ & $0.5110(0.0001)$ & $0.5008(0.0000)$ & $0.5005(0.0000)$ \\
\hline
\end{tabular}

TABle 7: The AEs and MSEs for $(\alpha=2.5 \text { and } \beta=3.5)^{T}$.

\begin{tabular}{|c|c|c|c|c|c|c|c|c|}
\hline$n$ & Par. & Est. & MLEs & MPSEs & PCEs & CVMES & ADEs & RTADEs \\
\hline \multirow{2}{*}{25} & $\widehat{\alpha}$ & $\begin{array}{c}\mathrm{AE} \\
\mathrm{MSE}\end{array}$ & $2.5676(0.2944)$ & $2.5444(0.2493)$ & $3.1695(2.0854)$ & $2.7040(0.7616)$ & $2.5868(0.3311)$ & $2.6072(0.3467)$ \\
\hline & $\widehat{\beta}$ & $\begin{array}{c}\text { AE } \\
\text { MSE }\end{array}$ & $3.5951(0.3132)$ & $3.5293(0.1982)$ & $4.6798(2.7572)$ & $3.5902(0.3670)$ & $3.5542(0.2382)$ & $3.5717(0.2741)$ \\
\hline \multirow{2}{*}{50} & $\widehat{\alpha}$ & $\begin{array}{c}\mathrm{AE} \\
\mathrm{MSE}\end{array}$ & $2.5186(0.1813)$ & $2.5082(0.1685)$ & $2.9012(1.1522)$ & $2.5475(0.2712)$ & $2.5375(0.2088)$ & $2.5907(0.3245)$ \\
\hline & $\widehat{\beta}$ & $\begin{array}{c}\text { AE } \\
\text { MSE }\end{array}$ & $3.5207(0.1824)$ & $3.5049(0.1645)$ & 3.7910 (1.9981) & $3.5154(0.1948)$ & $3.5075(0.1674)$ & $3.5087(0.1688)$ \\
\hline \multirow{2}{*}{100} & $\widehat{\alpha}$ & $\begin{array}{c}\text { AE } \\
\text { MSE }\end{array}$ & $2.5035(0.1636)$ & $2.5025(0.1623)$ & $2.7081(0.8632)$ & $2.5011(0.1609)$ & $2.5018(0.1616)$ & $2.5035(0.1636)$ \\
\hline & $\widehat{\beta}$ & $\begin{array}{c}\text { AE } \\
\text { MSE } \\
\end{array}$ & $3.5035(0.1633)$ & $3.5009(0.1608)$ & $3.5679(1.6502)$ & $3.5003(0.1602)$ & $3.5020(0.1618)$ & $3.5020(0.1618)$ \\
\hline
\end{tabular}

TABLE 8: List of some competitive models of CDFs.

\begin{tabular}{lcc}
\hline Model & CDFs of model & Author (s) \\
\hline W-PF & $G_{I}(x)=1-e^{-\alpha\left(x^{\beta} \beta_{\mathrm{g} 0}^{\beta} x^{\beta}\right)^{\gamma}}, \alpha, \beta, \gamma>0,0<x<\mathrm{g}_{0}$ & Tahir et al. [10] \\
ZTP-PF & $G_{I I}(x)=\frac{1-e^{-\alpha\left(x / g_{0}\right)^{\beta}}}{1-e^{-\alpha}}, \alpha, \beta>0,0<x<\mathrm{g}_{0}$ & Okorie et al. [58] \\
\hline
\end{tabular}

TABLE 9: Descriptive statistics for turbocharger data.

\begin{tabular}{lccccccrr}
\hline Nature & Min. & Q1 & Median & Mean & Q3 & Max. & Sk. & Kur. \\
\hline Turbocharger & 1.600 & 5.075 & 6.500 & 6.253 & 7.825 & 9.000 & -0.638 & 2.641 \\
\hline
\end{tabular}

TABLe 10: Parameter estimates, SEs, and goodness-of-fit statistics for turbocharger data.

\begin{tabular}{|c|c|c|c|c|c|c|c|}
\hline \multirow[b]{2}{*}{ Model } & \multicolumn{3}{|c|}{ Parameter estimates (SEs) } & \multicolumn{4}{|c|}{ Statistics } \\
\hline & $\widehat{\alpha}$ & $\widehat{\beta}$ & $\widehat{\gamma}$ & -LL & AIC & KS & $p$ value $(\mathrm{KS})$ \\
\hline EPF & $0.2516(0.6067)$ & $2.6418(0.7979)$ & - & 76.9082 & 157.8166 & 0.0496 & 1.0000 \\
\hline $\mathrm{W}-\mathrm{PF}$ & $1.2327(0.7999)$ & $3.1875(1.7180)$ & $0.7639(0.2057)$ & 77.6748 & 161.4164 & 0.0515 & 0.9999 \\
\hline ZTP-PF & $2.7724(0.5035)$ & $3.8728(0.5176)$ & - & 82.4755 & 168.9510 & 0.1253 & 0.5555 \\
\hline
\end{tabular}




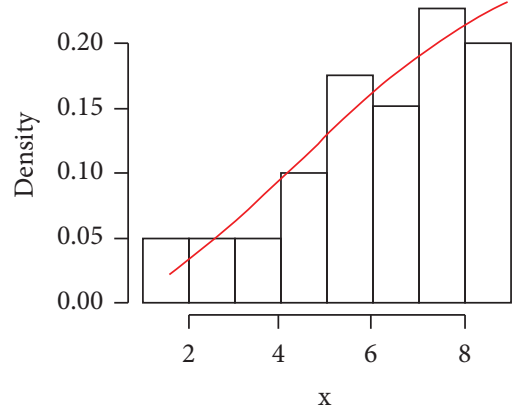

$-\mathrm{EPF}$

(i)

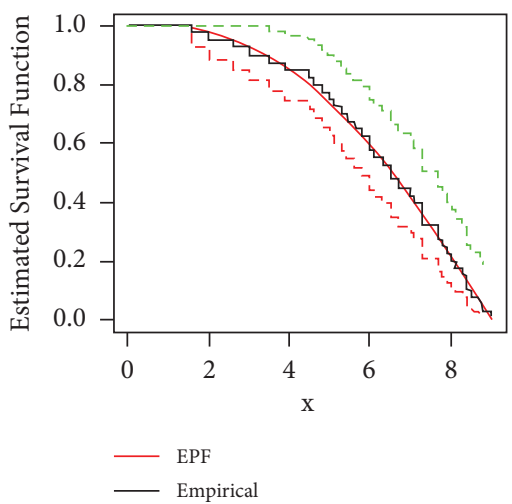

(iv)

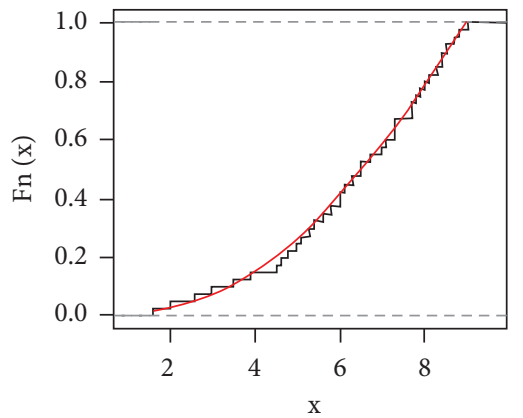

- EPF

(ii)

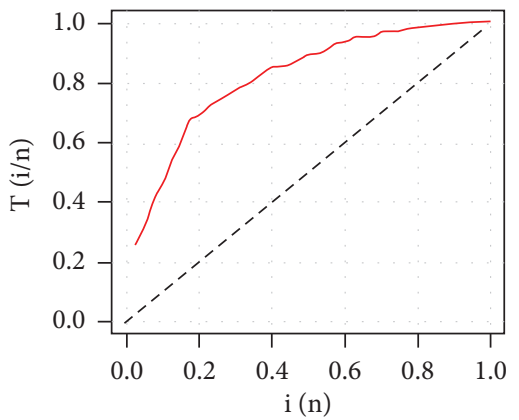

(v)

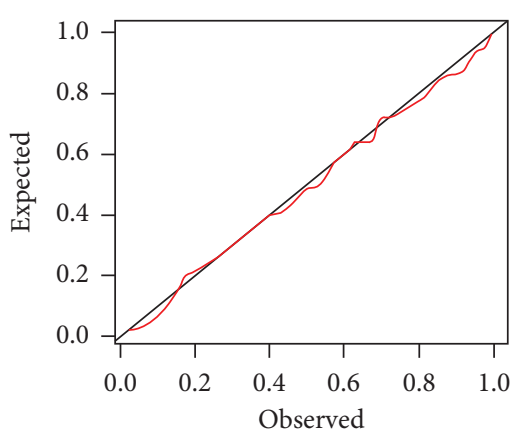

(iii)

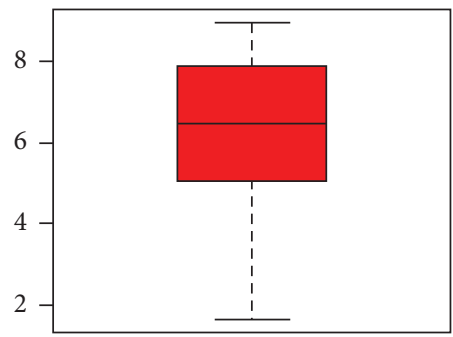

(vi)

FIgure 4: Fitted density (i), estimated CDF (ii), PP plot (iii), Kaplan-Meier survival (iv), TTT plot (v), and box plot (vi) for turbocharger data.

\section{Conclusions}

In this paper, we develop a new class that generates optimal univariate continuous models called the new exponentiated-G class. A special member of the proposed family called the exponentiated power function (EPF) distribution is studied in detail. Numerous statistical and reliability characteristics are discussed. Furthermore, the EPF distribution has flexible shapes for its density and hazard functions. For the estimation of EPF parameters, we followed the six accredited techniques named, MLEs, MPSEs, PCEs, CVMEs, ADEs, and RTADEs. A simulation experiment is performed to compare the performance of different estimation techniques. Our results show that the estimation techniques perform very well. The applicability of the EPF distribution is addressed using real-life data form the engineering field. The results show that the EPF distribution provides better fit as compared to other wellknown competitors.

For some possible future studies, the EPF distribution can be adopted to analyze entropy measures following the works of Siddiqui et al. [59] and Rashid et al. [60].

\section{Data Availability}

This work is mainly a methodological development and has been applied on secondary data; but if required, data will be provided.

\section{Conflicts of Interest}

The authors declare that they have no conflicts of interest.

\section{References}

[1] A. C. Dallas, "Characterizing the pareto and power distributions," Annals of the Institute of Statistical Mathematics, vol. 28, no. 1, pp. 491-497, 1976.

[2] M. Meniconi and D. M. Barry, "The power function distribution: a useful and simple distribution to assess electrical component reliability," Microelectronics Reliability, vol. 36, no. 9, pp. 1207-1212, 1996.

[3] J. Saran and A. Pandey, "Estimation of parameters of power function distribution and its characterization by the kth record values," Statistica, vol. 14, pp. 523-536, 2004.

[4] S. K. Chang, "Characterizations of the power function distribution by the independence of record values," Journal of The Chungcheong Mathematical Society, vol. 20, pp. 139-146, 2007.

[5] M. Tavangar, "Power function distribution characterized by dual generalized order statistics," Journal of the Iranian Statistical Society, vol. 10, pp. 13-27, 2011.

[6] M. Ahsanullah, M. Shakil, and B. M. G. Golam-Kibria, “A characterization of the power function distribution based on lower records," ProbStat Forum, vol. 6, pp. 68-72, 2013.

[7] G. M. Cordeiro and R. D. S. Brito, "The beta power distribution," Brazilian Journal of Probability and Statistics, vol. 26, pp. 88-112, 2012. 
[8] A. Zaka and A. S. Akhter, "Methods for estimating the parameters of the power function distribution," Pakistan Journal of Statistics and Operation Research, vol. 21, pp. 90-102, 2013.

[9] A. Al Mutairi, M. Z. Iqbal, M. Z. Arshad, B. Alnssyan, H. AlMofleh, and A. Z. Afify, "A new extended model with bathtubshaped failure rate: properties, inference, simulation, and applications," Mathematics, vol. 9, no. 17, p. 2024, 2021 p.

[10] H. M. Tahir, M. Alizadeh, M. Mansoor, G. M. Cordeiro, and M. Zubair, "The Weibull power function distribution with applications," Hacettepe Bulletin of Natural Sciences and Engineering, vol. 45, pp. 245-265, 2014.

[11] M. Naveed-Shahzad, Z. Asghar, F. Shehzad, and M. Shahzadi, "Parameter estimation of power function distribution with TL-moments," Revista Colombiana de Estadística, vol. 38, no. 2, pp. 321-334, 2015.

[12] M. Ahsan-ul-Haq, N. S. Butt, R. M. Usman, and A. A. Fattah, "Transmuted power function distribution," Gazi University Journal of Science and Technology, vol. 29, pp. 177-185, 2016.

[13] I. K. Okorie, A. C. Akpanta, and J. Ohakwe, "Marshall-Olkin extended power function distribution," European Journal of Statistics and Probability, vol. 5, pp. 16-29, 2017.

[14] I. B. Abdul-Moniem, "The Kumaraswamy power function distribution," Journal of Statistics Applications \& Probability, vol. 6, no. 1, pp. 81-90, 2017.

[15] A. Hassan, E. Elshrpieny, and R. Mohamed, "Odd generalized exponential power function distribution," Gazi University Journal of Science and Technology, vol. 32, pp. 351-370, 2019.

[16] A. Zaka, A. S. Akhter, A. Saeed Akhter, and R. Jabeen, "The new reflected power function distribution: theory, simulation \& application," AIMS Mathematics, vol. 5, no. 5, pp. 5031-5054, 2020.

[17] M. Z. Arshad, M. Z. Iqbal, and A. Al Mutairi, "Statistical properties of a new bathtub shaped failure rate model with applications in survival and failure rate data," International Journal of Statistics and Probability, vol. 10, pp. 1-49, 2021, p.

[18] M. Z. Arshad, M. Z. Iqbal, and M. Ahmad, "Exponentiated power function distribution: properties and applications," Journal of Statistical Theory and Applications, vol. 19, no. 2, pp. 297-313, 2020.

[19] A. Al Mutairi and M. Arshad, "A new odd Fréchet Lehmann type II-G family of distributions: a power function distribution with theory and applications," International Journal of Statistics and Probability, vol. 11, pp. 1-21, 2022.

[20] A. Al- Mutairi, "Transmuted weighted power function distribution," Pakistan Journal of Statistics and Operation Research, vol. 33, pp. 491-498, 2017.

[21] A. Alzaatreh, C. Lee, and F. Famoye, "A new method for generating families of continuous distributions," Metron, vol. 71, no. 1, pp. 63-79, 2013.

[22] J. U. Gleaton and J. D. Lynch, "Properties of generalized loglogistic families of lifetime distributions," Journal of Probability and Statistical Science, vol. 4, pp. 51-64, 2006.

[23] M. Bourguignon, R. B. Silva, and G. M. Cordeiro, "The Weibull-G family of probability distributions," Data Science Journal, vol. 12, pp. 53-68, 2014.

[24] A. Z. Afify, E. Altun, M. Alizadeh, G. Ozel, and G. G. Hamedani, "The odd exponentiated half-logistic-G family: properties, characterizations and applications," Chilean Journal of Statistics, vol. 8, pp. 65-91, 2017.

[25] M. H. Tahir, G. M. Cordeiro, A. Alzaatreh, M. Mansoor, and M. Zubair, "The logistic-X family of distributions and its applications," Communications in Statistics - Theory and Methods, vol. 45, no. 24, pp. 7326-7349, 2016.
[26] M. Aldahlan, M. G. Khalil, and A. Z. Afify, "A new generalized family of distributions for lifetime data," Journal of Modern Applied Statistical Methods, vol. 19, Article ID eP2948, 2021.

[27] M. Aslam, C. Ley, Z. Hussain, S. F. Shah, and Z. Asghar, "A new generator for proposing flexible lifetime distributions and its properties," PLoS One, vol. 15, no. 4, Article ID e0231908, 2020.

[28] O. S. Balogun, M. Z. Arshad, M. Z. Iqbal, and M. Ghamkhar, "A new modified lehmann type - ii g class of distributions: exponential distribution with theory, simulation, and applications to engineering sector," FloorResearch, vol. 22, pp. 1-24, 2021.

[29] A. Z. Afify, G. M. Cordeiro, H. M. Yousof, A. Alzaatreh, and Z. M. Nofal, "The Kumaraswamy transmuted-G family of distributions: properties and applications," Journal of Data Science, vol. 14, pp. 245-270, 2016.

[30] M. M. Mansour, G. Aryal, A. Z. Afify, and M. Ahmad, "The Kumaraswamy exponentiated Fréchet distribution," Pakistan Journal of Statistics and Operation Research, vol. 34, pp. 177-193, 2018.

[31] A. Mahdavi and D. Kundu, "A new method for generating distributions with an application to exponential distribution," Communications in Statistics - Theory and Methods, vol. 46, no. 13, pp. 6543-6557, 2017.

[32] M. Nassar, D. Kumar, S. Dey, G. M. Cordeiro, and A. Z. Afify, "The Marshall-Olkin alpha power family of distributions with applications," Journal of Computational and Applied Mathematics, vol. 351, pp. 41-53, 2019.

[33] M. Ijaz, S. M. Asim, M. Alamgir, M. Farooq, S. A. Khan, and S. Manzoor, "A Gull Alpha Power Weibull distribution with applications to real and simulated data," PLoS One, vol. 15, no. 6, Article ID e0233080, 2020.

[34] H. S. Klakattawi and W. H. Aljuhani, "A new technique for generating distributions based on a combination of two techniques: alpha power transformation and exponentiated T-X distributions family," Symmetry, vol. 13, no. 3, p. 412, 2021.

[35] A. Z. Afify, S. Ahmed, and M. Nassar, "A new inverse Weibull distribution: properties, classical and Bayesian estimation with applications," Kuwait Journal of Science, vol. 48, no. 3, pp. 1-10, 2021.

[36] A. Alsubie, M. Abdelhamid, A. Ahmed, M. Alqawba, and A. Afify, "Inference on generalized inverse-pareto distribution under complete and censored samples," Intelligent Automation \& Soft Computing, vol. 29, no. 1, pp. 213-232, 2021.

[37] Z. Ahmad, E. Mahmoudi, M. Alizadeh, R. Roozegar, and A. Z. Afify, "The exponential TX family of distributions: properties and an application to insurance data," Journal of Mathematics, vol. 2021, Article ID 3058170, 2021.

[38] Z. M. Nofal, E. Altun, A. Z. Afify, and M. Ahsanullah, "The generalized Kumaraswamy-G family of distributions," Journal of Statistical Theory and Applications, vol. 18, no. 4, pp. 329-342, 2019.

[39] H. M. Tahir and G. M. Cordeiro, "Compounding of distributions: a survey and new generalized classes," Journal of Statistical Theory and Applications, vol. 13, pp. 1-35, 2016.

[40] C. Chesneau, H. S. Bakouch, and M. N. Khan, "A weighted transmuted exponential distributions with environmental applications," Statistics, Optimization \& Information Computing, vol. 8, no. 1, pp. 36-53, 2020.

[41] A. L. Bowley, Elements of Statistics, Charles Scribner, New York, NY, USA, 4th ed. edition, 1920.

[42] J. J. A. Moors, "A quantile alternative for kurtosis," The Statistician, vol. 37, no. 1, pp. 25-32, 1988. 
[43] A. Rényi, "On measures of entropy and information," in Proceedings of the 4th Fourth Berkeley Symposium on Mathematical Statistics and Probability, pp. 547-561, Berkeley, CA, USA, July 1960.

[44] J. Havrda and F. S. Charvat, "Quantification method of classification processes: concept of structural-entropy," Kybernetika, vol. 3, pp. 30-35, 1967.

[45] A. Mathai and H. Haubold, "On a generalized entropy measure leading to the pathway model with a preliminary application to solar neutrino data," Entropy, vol. 15, no. 12, pp. 4011-4025, 2013.

[46] A. Basit, A. Riaz, Z. Iqbal, and M. Ahmad, "On comparison of entropy measures for weighted and truncated weighted exponential distributions," Advances and Applications in Statistics, vol. 50, no. 6, pp. 477-495, 2017.

[47] S. Dey, S. S. Maiti, and M. Ahmed, "Comparison of different entropy measures," Pakistan Journal of Statistics and Operation Research, vol. 32, pp. 97-108, 2016.

[48] M. Ijaz, S. N. AL-Aziz, S. M. Asim, J. G. Dar, and A. A. H. ElBagoury, "Comparison of different entropy measures using the relative loss approach for the lomax distribution," Information Sciences Letters, vol. 10, pp. 553-559, 2021.

[49] R. Cheng and N. Amin, Maximum Product of Spacings Estimation with Application to the Lognormal Distribution (Mathematical Report 79-1), University of Wales IST, Cardiff, UK, 1979.

[50] R. C. H. Cheng and N. A. K. Amin, "Estimating parameters in continuous univariate distributions with a shifted origin," Journal of the Royal Statistical Society: Series B, vol. 45, no. 3, pp. 394-403, 1983.

[51] J. H. K. Kao, "Computer methods for estimating Weibull parameters in reliability studies," IRE Transactions on Reliability and Quality Control, vol. 13, pp. 15-22, 1958.

[52] H. Cramér, "On the composition of elementary errors," Scandinavian Actuarial Journal, vol. 32, pp. 13-74, 1982.

[53] R. E. Von Mises, Wahrscheinlichkeit Statistik und Wahrheit, Springer, Basel, Switzerland, 1928.

[54] K. Xu, M. Xie, L. C. Tang, and S. L. Ho, "Application of neural networks in forecasting engine systems reliability," Applied Soft Computing, vol. 2, no. 4, pp. 255-268, 2003.

[55] A. Z. Afify, M. Alizadeh, M. Zayed, T. G. Ramires, and F. Louzada, "The odd log-logistic exponentiated Weibull distribution: regression modeling, properties, and applications," Iranian Journal of Science and Technology Transaction A-Science, vol. 42, no. 4, pp. 2273-2288, 2018.

[56] M. Nassar, A. Z. Afify, S. Dey, and D. Kumar, "A new extension of Weibull distribution: properties and different methods of estimation," Journal of Computational and Applied Mathematics, vol. 336, pp. 439-457, 2018.

[57] P. Rafael, M. Bourguignon, C. Rafael, Adequacy Model: Adequacy Of Probabilistic Models And General Purpose Optimization. R Package Version 2.0.0. 2016. Available online: https://CRAN.R-project.org/package=AdequacyModel.

[58] I. E. Okorie, A. C. Akpanta, J. Ohakwe, D. C. Chikezie, C. U. Onyemachi, and M. K. Rastogi, "Zero-truncated Poisson-power function distribution," Annals of Data Science, vol. 8, no. 1, pp. 107-129, 2021.

[59] M. K. Siddiqui, S. Manzoor, S. Ahmad, and M. K. A. Kaabar, "On computation and analysis of entropy measures for crystal structures," Mathematical Problems in Engineering, vol. 2021, pp. 1-16, Article ID 9936949, 2021.

[60] M. A. Rashid, S. Ahmad, M. K. Siddiqui, and M. K. A. Kaabar, "On computation and analysis of topological index-based invariants for complex coronoid systems," Complexity, vol. 2021, pp. 1-12, Article ID 4646501, 2021. 